\title{
THE USE AND RATIONALE OF SELECTIVE ALPHA BLOCKADE IN CHILDREN WITH NON-NEUROGENIC NEUROGENIC BLADDER DYSFUNCTION
}

\author{
GUY BOGAERT, GOEDELE BECKERS, RITA LOMBAERTS \\ Department of Urology, Pediatric Urology, Department of Pediatric Nephrology and Transplantation, UZ \\ Leuven, Belgium, and Department of Pediatric Urology, Linz, Austria
}

\begin{abstract}
Introduction: We present here a long-term observation of 2 children with a rare syndrome with a non-neurogenic neurogenic bladder dysfunction (Hinman's syndrome), and we investigated the safety and efficacy of long-term use of terazosine in association with prophylactic antibiotics, timed voiding and a bowel regimen.

Materials and Methods: Two children, 7 years-old $(22 \mathrm{~kg})$ and 11 years-old $(36 \mathrm{~kg})$ presented in 1997 to our pediatric urology clinic with symptoms of urgency, frequency, urge incontinence and nocturnal enuresis. Both children were placed in a regimen of terazosine (starting with $0.5 \mathrm{mg}$ increasing until $2 \mathrm{mg}$ ).

Results: There were no significant side effects throughout the entire treatment. The first 7year old boy however developed some dizziness when the dose of terazosine was increased to $2 \mathrm{mg}$ (after 4 weeks of administrating $1 \mathrm{mg}$ ), and this disappeared immediately when the dosage was reduced back to $1 \mathrm{mg}$ daily. The urgency symptoms improved in both boys after 3 weeks of $1 \mathrm{mg}$ terazosine. The secondary enuresis in the 11 year-old boy resolved after 2 months of $2 \mathrm{mg}$ terazosine.

Conclusion: It is possible to say that the alpha-blocker medication, terazosine can be administered safely to children with a non-neurogenic bladder dysfunction, also known as the Hinman's syndrome. These results have shown that dysfunctional voiding, postvoiding residual and upper tract involvement can disappear over time when long term terazosine is given in combination with timed voiding, prophylactic antibiotic therapy and treatment of the associated constipation. Our observations also suggest a permanent effect after discontinuing the medication.
\end{abstract}

Key words: bladder, neurogenic; voiding dysfunction; children; enuresis; adrenergic alpha-antagonists

Int Braz J Urol. 2004; 30: 128-134

\section{INTRODUCTION}

Frank Hinman described in 1973 the rare syndrome with a non-neurogenic neurogenic bladder dysfunction in children (1). Since then, several articles have been published on this syndrome and its treatment (2-4). The symptoms are variable, ranging from frequency to severe incontinence. In addition, the videourodynamic findings may vary from mild detrusor overactivity and little postmicturition residue to severe bladder dysfunction associated with end stage renal failure. The most typical finding is of functional bladder outlet obstruction or detrusor sphincter dyssynergia although there is no anatomic correlation. Most importantly, there is no neurologic abnormality. Associated problems such as behavioral and psychosocial problems and bowel dysfunction, especially constipation are also seen in the Hinman 
syndrome. All the components must be included in the diagnostic and treatment approach.

Stockamp, in 1975, first described the use of a non-selective $\alpha$-blocker in non-neurogenic bladder outlet dysfunction (5). In 1992 the use of the non-selective $\alpha$-blocker phenoxybenzamine was reported in combination with urinary diversion in the Hinman syndrome as a partial success (6). The phenoxybenzamine medication never gained popularity because of the severe side effects such as hypotension and dizziness.

More recently, selective $\alpha$-blocker medication have been successfully administered in patients with lower urinary tract symptoms (LUTS) and benign prostatic hypertrophy (BPH) without a significant incidence of the feared side effects like hypotension and dizziness. However, the use of these drugs in children is not common because of the limited indication and the very small number of children with the Hinman syndrome. In addition, there are no doseresponse studies published on selective alpha-blocking medication in children.

In this long-term observation of 2 children with the Hinman syndrome, we investigated the safety and efficacy of long-term use of terazosine in association with prophylactic antibiotics, timed voiding and a bowel regimen.

\section{MATERIALS AND METHODS}

Two children, $7(22 \mathrm{~kg})$ and 11 years $(36 \mathrm{~kg})$ old presented in 1997 to our pediatric urology clinic with symptoms of urgency, frequency, urge incontinence and nocturnal enuresis.

The first 7-year old boy presented with a longstanding daytime voiding problem and enuresis. Although he became dry during daytime at 2.5 years of age, he always had urgency and he was never dry at night. He had also suffered from chronic constipation since birth. His physical exam, including a specific neurological evaluation of the lower extremities, was normal. Urine and blood analysis for renal function was normal. His maximum flow rate was $5.3 \mathrm{ml} / \mathrm{sec}$ with a post void residual of $130 \mathrm{ml}$. In his voiding diary, he recorded daytime volumes between 50 and $270 \mathrm{ml}$. He was wearing diapers at night and after weighing the diapers together with the first void in the morning, he produced between 200 and $300 \mathrm{ml}$ urine during the night. Ultrasound showed a left hydro-ureteronephrosis and marked bladder wall thickening. Intravenous urography (IVU) additionally showed a "Christmas-tree" shaped bladder (Figure1). Video-urodynamic examination showed a poorly compliant bladder, an open bladder neck, no hyperreflexia, high voiding pressures (the maximum detrusor pressure was $53 \mathrm{~mm} \mathrm{H}_{2} \mathrm{O}$ ) and detrusor/sphincter dyssynergia. Magnetic resonance imaging (MRI) of his spine and brain was normal. A DTPA-scan with furosemide-administration $(0.5 \mathrm{mg} / \mathrm{kg}$ body weight $)$ showed delayed excretion at the left kidney, a total GFR of $73 \mathrm{~mL} / \mathrm{min} / 1.73 \mathrm{~m}^{2}$ and a normal differential renal function.

A treatment regimen with oxybutinin $0.1 \mathrm{mg} /$ $\mathrm{kg}$ body weight three times a day, nitrofurantoin 2 $\mathrm{mg} / \mathrm{kg}$ at bedtime, aggressive treatment of his constipation, timed voiding and physiotherapy was initi-

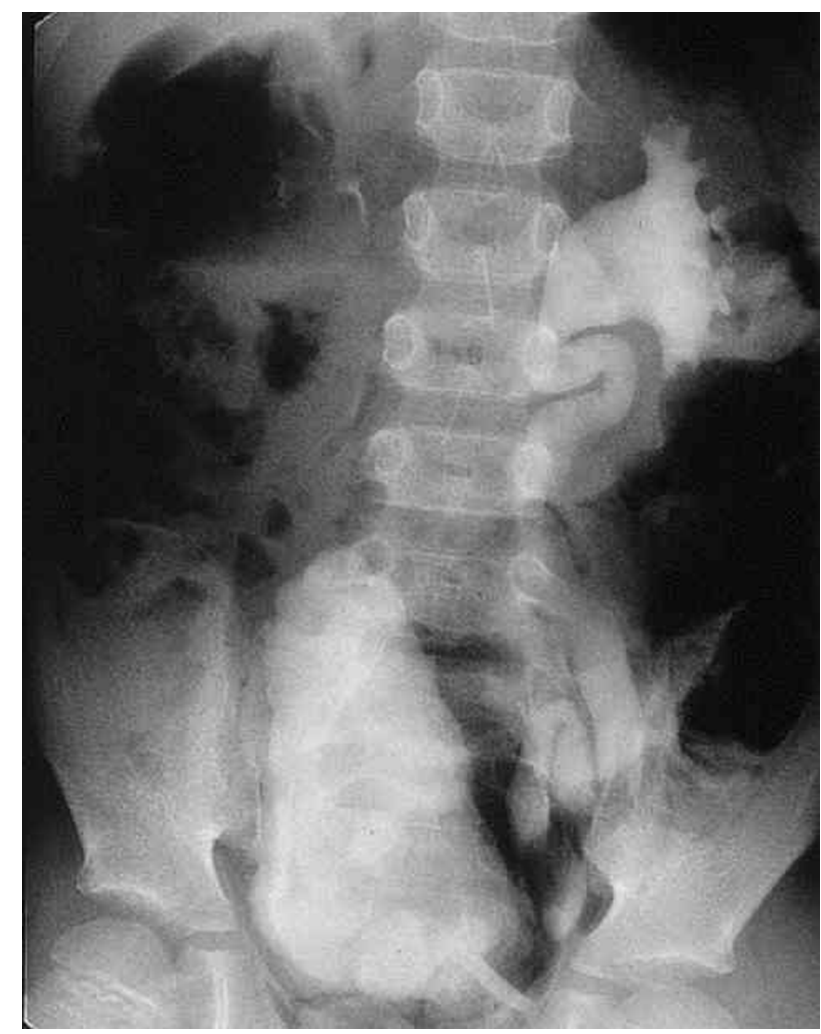

Figure 1 - Picture of the dilated left ureter and the thick-walled bladder and the Christmas-tree shaped bladder of the 7 yearsold boy. 
ated. However, after 8 weeks, his treatment seemed unsuccessful, as the voiding symptoms including persistent postvoid residual volumes between 140 - 200 $\mathrm{mL}$ and the hydroureteronephrosis did not improve. The option of clean intermittent catheterization (CIC), was refused by the boy and his family. The option of treatment with an uroselective alpha blocker terazosine was discussed including possible side effects and the fact that there were no dose response studies known in children. A dosage of $0.5 \mathrm{mg}$ terazosine at bedtime was started, the oxybutyine medication was stopped and the constipation treatment and physiotherapy was continued. Because the medication was well tolerated without any side effects, the dosage was increased to $1 \mathrm{mg}$ terazosine at bedtime after 2 weeks. Another 4 weeks later, the dose was further increased to $2 \mathrm{mg}$ but because of dizziness it was immediately discontinued and $1 \mathrm{mg}$ continued. The urological symptoms resolved and imaging appearances returned to normal. Terazosine was
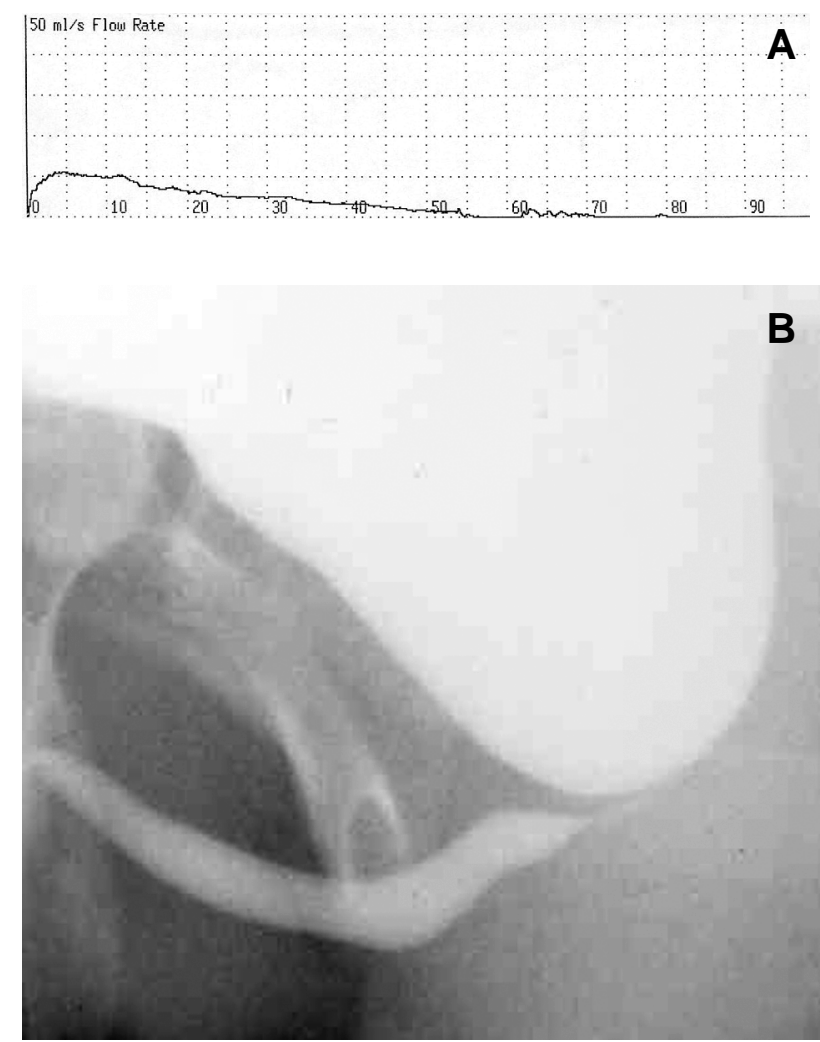

Figure 2 - Urinary flow (A) and voiding cystourethrogram (B) of the 11 year-old boy before treatment. stopped after 32 months of treatment. The boy is now 12 years old and is still followed every 6 months. He takes currently no medication and is symptom free.

The second boy was 11-year old when he came to our clinic and he presented with a secondary nocturnal enuresis for 4 months. He was born with a tetralogy of Fallot for which he underwent cardiac surgery at 2 years of age. He was dry day and night at 2 years of age, but he always had some urgency and frequency and a tendency to constipation. His physical exam, including a clinical neurological evaluation, was normal. His urine was clear, microscopic evaluation of the urine was normal and the urine culture negative. The maximal flow rate at presentation was $8 \mathrm{ml} / \mathrm{sec}$ with a postvoiding residual volume of $240 \mathrm{ml}$ (Figure-2). Blood analysis showed an elevated urea of $70 \mathrm{mg} / \mathrm{dl}$ and a creatinine of $1.91 \mathrm{mg} / \mathrm{dl}$. His creatinine clearance was $32 \mathrm{ml} / \mathrm{min} / 1.73 \mathrm{~m}^{2}$. A proteinuria of $188 \mathrm{mg} / 24$ hours was noted. His voiding diary he recorded daytime voided volumes between 100 and $300 \mathrm{~mL}$. On ultrasound he was noted to have bilateral hydro-ureteronephrosis, bilateral renal parenchymal atrophy and increased bladder wall thickness (Figures-3 and 4). Unfortunately, due to technical problems he did not undergo a videourodynamic evaluation. However, he did have a voiding cystourethrogram (VCUG) where a spindle-shaped dilation of the proximal urethra was seen.

Nitrofurantoin $2 \mathrm{mg} / \mathrm{kg}$ at bedtime, aggressive treatment of his constipation, timed voiding and

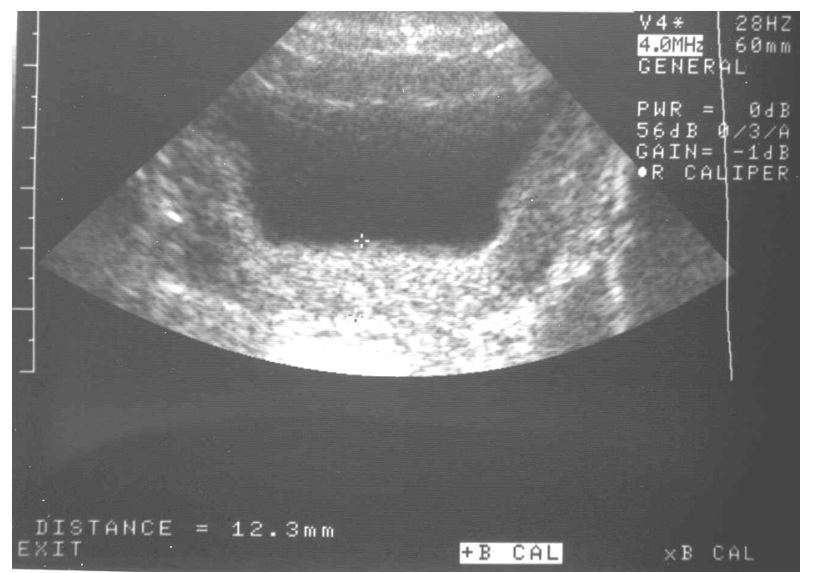

Figure 3 - Ultrasound of the thick-walled bladder of the 11 year old boy. 


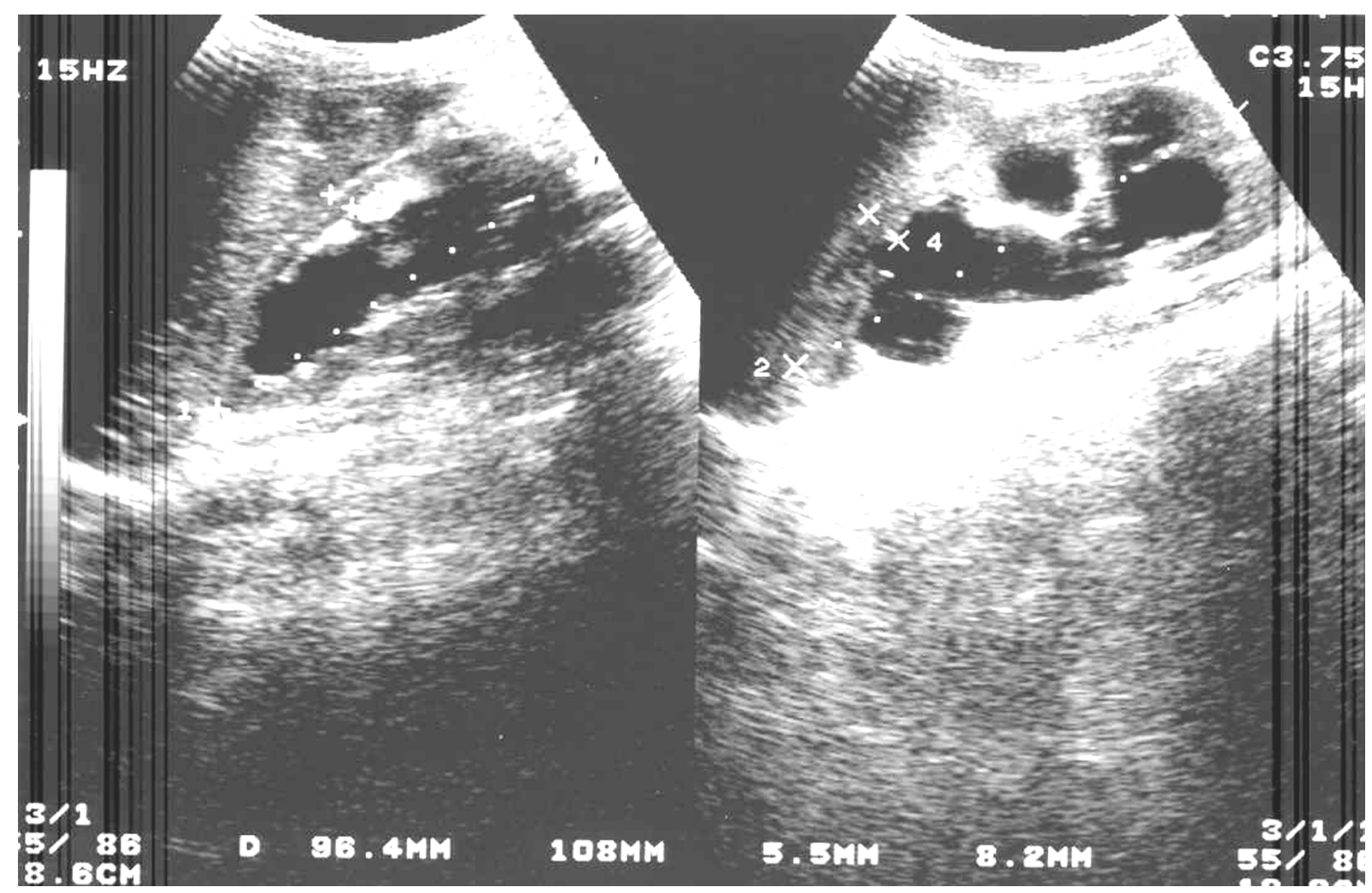

Figure 4 - Ultrasound of the hydroureteronephrosis and thinned parenchyma of the 11 year old boy.

physiotherapy failed to produce any improvement in 8 weeks. CIC was refused by the boy and his family. After similar counseling terazosine, $0.5 \mathrm{mg}$ at bedtime was added to the other treatment regimen. For 2 weeks of medication, there were no problems or side effects of therefore the dosage was increased to $1 \mathrm{mg}$ terazosine. After another month of treatment with 1 mg terazosine and no side effects, the dose was increased to $2 \mathrm{mg}$. The patient remained on this dosage for 25 months. Prophylaxis and physiotherapy were stopped after 12 months.

Both children have now discontinued the medication for more then 18 months and remain symptom free.

\section{RESULTS}

During the entire treatment with terazosine, special attention regarding potential side effects of $\alpha$-blocker medication was addressed to the children and their parents: postural hypotension, dizziness, headache and rhinitis. However, there were no significant side effects throughout the entire treatment. The first 7-year old boy however developed some dizziness when the dose of terazosine was increased to $2 \mathrm{mg}$ (after 4 weeks of administrating $1 \mathrm{mg}$ ), and this disappeared immediately when the dosage was reduced back to $1 \mathrm{mg}$ daily.

The urgency symptoms improved in both boys after 3 weeks of $1 \mathrm{mg}$ terazosine. The secondary enuresis in the 11-yr old boy resolved after 2 months of $2 \mathrm{mg}$ terazosine.

Dilation of the upper urinary tract improved in both boys after 4 months of terazosine 1 and $2 \mathrm{mg}$ treatment respectively.

Post voiding residual volume was the last symptom to improve. Volumes diminished after 6 months of terazosine $1 \mathrm{mg}$ treatment in the 7-year old boy and in the 11-year old boy, it improved after 9 months of treatment $(2 \mathrm{mg})$. At the same time, dis- 
tinct improvement of the urinary flow was observed and this amelioration persisted during treatment and after discontinuing the medication (Figure-5).

The creatinine clearance remained stable at $73 \mathrm{ml} / \mathrm{min} / 1.73 \mathrm{~m}^{2}$ in the 7 years old boy whereas in the 11 years old one it improved from $32 \mathrm{ml} / \mathrm{min} /$ $1.73 \mathrm{~m}^{2}$.

After discontinuing the terazosine medication, both boys had further stable renal function without residual hydronephrosis. They have almost normal appearing bell shape urinary flows and the residual post-voiding volumes remain below $30 \mathrm{ml}$.

\section{DISCUSSION}

This long-term observation in two children has shown that $\alpha$-blocker-medication terazosine 1 - 2 mg daily can be an important adjunct in treating voiding dysfunction in children with non-neurogenic neurogenic bladder dysfunction and that the medication can be given safely over a longer period.

Until today, there has been no confined etiology for the Hinman syndrome found. However, there is a trend that nowadays we are confronted with earlier stages of the syndrome. This might be due to the fact that back in 1973 children with bladder function problems consulted their physician very late compared to today. In the situation of end stage renal disease, only urinary diversion, bladder augmentation and renal transplantation were possible options. As these children are nowadays seen in an earlier stage without end stage renal disease but with severe bladder and bowel function problems, attempts with medication, clean intermittent catheterization and other non surgical methods are used to avoid renal deterioration.

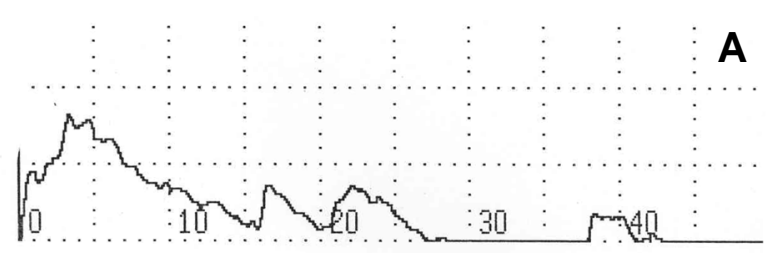

The rationale for giving $\alpha$-blocker-therapy in case of voiding dysfunction was given by Krane et al. in $1973(7,8)$ showing that bladder emptying significantly improved after phenoxybenzamine was administered to children with neuropathic bladder dysfunction. In children without neurological abnormalities, Stockamp was the first in 1975 to report the successful use of phenoxybenzamin in the situation of upper tract complications due to functional infravesical obstruction (5). Upper urinary tract dilatation improved in 3 out of 5 children. De Vooght in 1976 (9) found that the best results of $\alpha$-blockertherapy were seen in children with neuropathic bladder dysfunction with increased urethral outflow resistance associated with absent or slight detrusor activity.

Side effects of non-selective $\alpha$-blocker medication such as hypotension, dizziness and headache has limited the general clinical use. The introduction of selective $\alpha$-blocker medication such as terazosine has opened a new treatment option regimen in patients with functional bladder outlet obstruction. The first group of patients that would benefit from such a treatment was patients with lower urinary tract symptoms (LUTS) due to benign prostatic hypertrophy (BPH) and this has been clinically confirmed. However, the experience of selective $\alpha$-blockers in children is limited. Austin et al. has reported in 1999 a short term follow up study with the use of $1 \mathrm{mg}$ of doxazosine in children with the Hinman syndrome, with good results in 1 patient out of 4 (4).

Terazosine $1-2 \mathrm{mg}$ was chosen in our treatment alternative for the treatment of functional bladder outlet obstruction in our pediatric patients because terazosine is a selective $\alpha_{1}$-blocker for which no cellapoptosis has been described. It is known that the

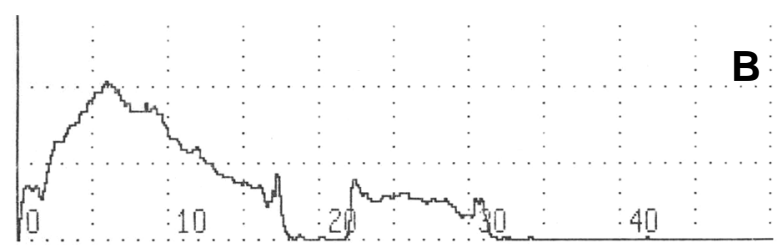

Figure 5 - Improved urinary flow of both boys after 6 months of treatment with terazosine; 7 year-old boy (A) and 11 year-old boy (B). 
average dose of terazosine in adults is $5 \mathrm{mg}$ for an adult of $70-80 \mathrm{~kg}$, therefore the dosage for our patients was calculated as $1 \mathrm{mg}$ terazosine per $20 \mathrm{~kg}$ body weight. This calculation appeared to be correct as in the first $7 \mathrm{yr}$ old boy whose weight was $22 \mathrm{~kg}$ and he received $1 \mathrm{mg}$ terazosine whereas he experience some dizziness when he took $2 \mathrm{mg}$. The second $11 \mathrm{yr}$ old boy weighted $36 \mathrm{~kg}$ and had good results without side effects with the dosage of $2 \mathrm{mg}$ terazosine.

The fact that terazosine has such a long term beneficial effect on the bladder function in these both children remains somewhat hypothetical. One might argue that if these children did not have Hinman syndrome. The difference between functional bladder outlet obstruction and detrusor sphincter dyssynergia is not always a clear cut. However, in our patients, the classical presentation and imaging appearances makes the diagnosis most probable. In addition, these patients might have developed more severe symptoms but for our early diagnosis, they might be cured now.

The exact etiology of the Hinman-Syndrome is not known and therefore it is unknown if the $\alpha_{1}$ adrenoreceptors would play a role in this matter. De Groat described the modulation of voiding and storage reflexes by activation of $\alpha_{1}$-adrenoreceptors in animals (10). This study described the predominance of $\alpha_{1}$-presynaptic bladder modulation in the bladder body of young rats, and a $\alpha_{1}$-postsynaptic predominance in the bladder base of older rats. In addition, in humans urethral $\alpha$-adrenoreceptors have been described and they are supposed to mediate contraction and assist in the maintenance of urinary continence (11). It is also known that excitatory neuromuscular transmission in the urinary bladder arises predominantly through activation of the parasympathetic pathways. Cholinergic transmission plays a role in regulating the residual urinary volume at the end of a voiding cycle, and inhibitory sympathetic transmission in the detrusor is important during the filling phase. Sympathetic nerves may act on parasympathetic nerve terminals and inhibit cholinergic and non-cholinergic excitation (12).

The possible associated problems of the Hinman syndrome such as behavioral and psychoso- cial problems may also have an influence on bladder and bowel function problems. Behavioral problems might cause a "stress-induced" elevated sympathetic tonus inducing sphincter dyssynergia, an elevated bladder tonus and an elevation of the post-micturition residual urine.

This supports the hypothesis of the benefit of the $\alpha$-blocker-therapy that could help in regaining a normal micturition pattern. Secondary to the improved bladder function, the bladder wall thickness might decrease and will secondarily improve the upper tract drainage.

This is exactly what happened in our patients.

The observation that it took more than 3 weeks to improve the urgency voiding symptoms, 4 months to improve renal drainage and even 9 months to see effect on postvoid residual and urinary flow explain the long standing and complex etiology of the syndrome. Although all these symptoms occurred in the identical time frame further observations in larger patient groups will demonstrate if these effects will be consistent.

After discontinuing the medication for more then 18 months, the patients did not relapse to their previous bladder function problem. There is no exact explanation for this permanent action. It is also unknown if the medication could have been stopped earlier and still have had beneficial effect. In addition, the functional bowel problems have been resolved with the treatment regimen. Because of the other factors such as the physiotherapy, the attention and motivation, these children received during the treatment it is not certain how important each of the treatment factors are.

In conclusion it is possible to say that the alpha-blocker medication, terazosine can be administered safely to children with a non-neurogenic bladder dysfunction, also known as the Hinman syndrome. These results have shown that dysfunctional voiding, postvoiding residual and upper tract involvement can disappear over time when long term terazosine is given in combination with timed voiding, prophylactic antibiotic therapy and treatment of the associated constipation. Our observations also suggest a permanent effect after discontinuing the medication. 


\section{REFERENCES}

1. Hinman F, Baumann FW: Vesical and ureteral damage from voiding dysfunction in boys without neurologic or obstructive disease. J Urol. 1973; 109: 727-32.

2. Rapariz Gonzalez, MA: Sphincter reeducation in noncoordinated urination syndrome. Arch Esp Urol. 1997; 50: 625-32.

3. Maizels M, King LR, Firlit CF: Urodynamic biofeedback: A new approach to treat vesical sphincter dyssynergia. J Urol. 1979; 122: 205-9.

4. Austin PF, Homsy YL, Masel JL, Cain MP, Casale AJ, Rink RC: Alpha-adrenergic blockade in children with neuropathic and non-neuropathic voiding dysfunction. J Urol. 1999; 162: 1064-7.

5. Stockamp K: Treatment with phenoxybenzamine of upper urinary tract complications caused by intravesical obstruction. J Urol. 1975; 113: 128-31.

6. Breuer J, Foll J, Renz-Polster H, Rebmann H, Rosendahl W, Wilbert D: Hinman syndrome. Pronounced renal failure as a sequel of pseudo-neurogenic disorder of bladder emptying. Monatsschr Kinderheilkd. 1992; 140: 162-5.

7. Krane RJ, Olsson CA: Phenoxybenzamine in neurogenic bladder dysfunction. I. A theory of micturition. J Urol. 1973; 110: 650-2.

8. Krane RJ, Olsson CA: Phenoxybenzamine in neurogenic bladder dysfunction. II. Clinical considerations. J Urol. 1973; 110: 653-6.

9. de Voogt HJ, Van der Sluis C: Preliminary evaluation of alpha-adrenergic blocking agents in children with neurogenic bladder due to myelomeningocele. Dev Med Child Neurol Suppl. 1976; 37: 82-8.

10. de Groat WC, Yoshiyama M, Ramage AG, Yamamoto T, Somogyi GT: Modulation of voiding and storage reflexes by activation of alpha1-adrenoceptors. Eur Urol. 1999; 36: 68-73.

11. Koyanagi T: Studies on the sphincteric system located distally in the urethra: The externa urethral sphincter revisited. J Urol. 1980; 124: 400-6.

12. Rushton DN: Handbook of Neuro-Urology. London, Marcel Dekker Inc., England. 1994; p. 404.

Received: November 12, 2003

Accepted after revision: December 20, 2003

\author{
Correspondence address: \\ Dr. Guy Bogaert \\ Dept Urology, Pediatric Urology \\ Herestraat 49, B-3000 \\ Leuven, Belgium \\ Fax: + 32 1634-6931 \\ E-mail: guy.bogaert@uzleuven.br
}

